\title{
Conceptualizing Compassionate Power
}

\author{
Paul M. Wishart, BSc, PhD, MA \\ Published in Spirituality and Health International 2005, 6: p. 33-38
}

\begin{abstract}
Summary
A contrast is made between living a life based upon what might be called polarized "power to", the dualistic “power over” or "power under”, and a life based upon "power with”, power that is shared, in and through compassion. "Power over" and "power under" are "relationships to" which keep us attached and tethered to our ego, to the past and/or the future. "Power with", being grounded in and through compassion, is characterized as that transcending power connecting each of us with the imbalance and chaos of growth and healing, as One.
\end{abstract}

\section{Introduction}

As the first step in this manuscript, I wish to present how the terms "power”, “conceptualization”, and "compassion" are understood:

"Power" is a presence of energy, and is usually associated with the ability "to do" something, light a house, propel a car, breathe. Power is taken as a property we possess inherent in the very act of being alive, at the very basic level of being able to breathe. In that we are able to breathe in and breathe out, this is reflective of our inborn nature of possessing power.

"Conceptualizing" is used in the context in which it is used in Grounded Theory as articulated by Dr. Barney Glaser ( 2002). The intent in conceptualizing is not just to describe a phenomenon, but to provide a trajectory to discern the martialing of power in our relationships. The intent is to connect the theory of power in relationships to practice. Theory without practice, power without compassion, the inter-connectedness and integration of the two will be a position that this paper will highlight.

"Compassion" is a word that permeates many of the great "wisdom traditions" of the world religions, and for good reason. Compassion as it is used in this article is that deep connection of "being with" ourselves and others, in suffering, in joy, in life. Where suffering often seems to be so pervasive, the dukkha in the Buddhist tradition, the meaning of compassion will be tethered as "being in relationship with" life and living, across the spectrum of suffering and joy.

This paper will conceptualize how power is governed or martialed in the context of relationships, as a means of connecting theory and practice. The premise of this paper is that through connecting and an awareness of the interpenetration of "power with" relationships, we are empowered to have life, and to have it more abundantly, physically, mentally, emotionally, and spirituality.

\section{A Conceptualization of Compassionate Power}

Power can be understood and experienced at different levels of relationship within our lives. One relationship that we may have with power is a very strong dualistic one, having the perception of having power or not having it, a presence or absence of power. This one often has an unbalanced spin to it, tending strongly to polarization. Another relationship we may have is a relationship with power, that is life-giving and nurturing, of a centering, balancing, soft, flowing, loving, harmonious 
nature.

My understanding of the unbalanced dynamic of power is that it arises out of one's identification with the ego and its self-centered needs. In this context ego is dualistic and polarized by its very nature, and speaks from and to imbalance. In this dualistic framework, the ego infers or creates a relationship to power. Patterns of relating to power depend upon how the ego perceives its benefits "in relationship to" the other aspect or pole of the relationship. I see this type of relationship so often in society and in my own life. One pole is that of people who have power over another. The other complementary pole is that where people seem to be without power, and are under another.

There can be situations where there are a multiple of "power states" existing simultaneously in the one relationship. The point that I try to focus on is that if I find myself polarized on one pole or the other; power "over" or power "under", both poles can be constructed to serve the needs of the ego as a means of the ego controlling circumstances or of the ego being recognized.

The power "over" extreme is one that seems pretty obvious. If I have power "over” you, it is much easier for me to "appear" to control you. As a consequence of this perception, my world in this aspect of relationship can have the "appearance", and I state here clearly it is the "appearance", of the relationship being controlled and stable.

If on the other hand, I perceive others to have power over me, or I am giving another power over me, this is another way of my ego trying to maintain control. I would like to state here that this perspective of maintaining control through another having power over me may not work for everyone. It may be inaccurate, or unpalatable for some. I will speak personally here, if it is not generalizable, that is fine.

In my patterns of interaction with those who have held power over me, I have realized that I am doing my best to keep things stable and not "rock the boat" by keeping silent and leaving the piloting of the boat to someone else other than myself. Sometimes the strength of this pattern of interaction is so strong that I am not up to expending the physical, mental, emotional, intellectual, or spiritual energy that I "think" it would take to break this pattern. I am reminded of a quotation which sheds light upon the energy of breaking patterns; the "thinking" part. The quotation speaks to why we might not wish to break the pattern, and the implicit deterrent that might prevent us from actively seeking to change such patterns of interaction. "It is not work, but the thought of work that makes the lazy man [or woman] tired.” This “thinking” process could be compared to what St. Teresa refers to as imperfect sleep, "Like imperfect sleep, which, instead of giving more strength to the head [and for me the heart] doth leave it the more exhausted, the result of mere operations of the imaginations is but to weaken the soul.” (James 1958).

Now, if you like, contrast what I have just described, what might be called polarized power dynamics, with a centered, balancing, harmonious dynamic of power. This power is characterized as a transcending power, "power with" (compared to the dualistic “over" or "under”). I personally believe that such a power is ultimately derived from, through, and within that which "is" greater and less than ourselves, be "It" named as that which is Other, God, Creator, Christ, Buddha, Tao, Spirit, Holy One, Emptiness, Void, Nothing, Everything, ...

Characteristics which have been determined to be associated with this transcendent power are: Grace, Love, Harmony, Peace, Shalom, Wu Wei, At-one-ment, Humility, as examples. In the Christian tradition, in which I more or less find myself, this power is defined by the fruits of the Spirit, as are found in Galatians 5: 22-23, "But the fruit of the Spirit is love, joy, peace, patience, kindness, goodness, faithfulness, gentleness, and self-control. Against such things there is no law."

Power "over" and power "under" are limited, closed visions of who we "think" we are, in relationships with ourselves and with others, and quite possibly with the relationships we have or 
don't have with the Other named variously above.

"Power with" is an unlimited, open vision or system, not only of who we are, but also of who we are becoming in the future, and who we were in the past. This open vision even encompassed the "why" of our being here, which might seem like a long stretch at times. Power "over" and power "under" keep us in the box, in our limited, and often time worn and time weary perceptions of whom we are. We can keep ourselves isolated and insulated to various degrees of un-health and dis-ease. We are unable to grow, to heal, to be whole, to be transformed. "Power with" allows us to open up to the potential in our box, in our humanity and humanness, in our relational perceptions of who we are. "Power with" allows us to be part of an amazing paradox, to be able to step outside the box while still being in it, to transcend our identity of who we "think" we are, and to be part of the unfolding transformation, healing, and wholeness of the universe. I believe that it is through such a context or realm of "power with" that (our) transformation is facilitated, that we are made new. It is through such relationships that healing and acceptance, both of self and others, love, compassion, faith, hope, trust, integration, growth, freedom, liberation, and distant non-local events occur.

If this sounds pretty positive, I believe that this is from where hope springs eternal. "Power with" allows movement and freedom through all events and circumstances, not just in good, not just in bad, but through both. Power "over" and power "under" keep us attached and tethered to our ego, to the past or the future. We become attached to a limiting definition or vision of who we are, and of how we have to control all things around us to provide us with the perception of comfort, security, and stability. "Power over" and "power under" relationships often keep us resistant to the imbalance and chaos around us, preventing those nudges from the Creator from moving us, from working through us, within us, around us. We are prevented, and very often we prevent ourselves, from working toward and for our ultimate good. We become so wrapped up in our-selves, in our needs and wants, in our old patterns of interactions, that we become paralyzed or anesthetized to life, not only to our own life, but to the lives of others.

If we can't let go of these attachments to unbalanced power dynamics (and this takes practice!), we cannot be open to life unfolding around us and within us. As I see it, if we cannot see the forest for the trees, we cannot "see". Life is a koan, or a paradox. All too often I lose sight of this, and I miss the humour of life. If we are able, through practice and grace, to transcend our understanding of ourselves as just our physical bodies, as just our thoughts, we apprehend a glimpse of who we are being called to become. This is just the opening, the invitation to the dance, to the journey. At this dance, on this journey, we are both the guest and the host, the tourist and the guide.

The danger to this invitation is that we may feel that we are (I am) the only one called to this journey, this dance. I truly believe that we are called to the dance, to take part in the journey, to be, to become; to become as we are through grace and self-acceptance. But we have (I have) to acknowledge that we all, to some degree, greater or lesser, have free choice in the matter of accepting or rejecting this invitation. There are many opportunities during the dance, during the journey, to accept or reject these invitations. Hence the admonition, the call, to vigilance and discernment in the New Testament, in Matthew 24:36, "Therefore keep watch, because you do not know the day or the hour."

As I have indicated above, one of the dangers is that we will not discern or accept the invitation, or that we will ignore it. This might be understood as having happened in the following comment in the Pronouncement of the Rich Young Ruler, Mark 10: 17-22, in particular verses 2122. "Jesus looked at him and loved him. 'One thing you lack,' he said. 'Go, sell everything you have and give to the poor, and you will have treasure in heaven. Then come, follow me.' At this the man's face fell. He went away sad, because he had great wealth (attachment)." We have the 
invitation, but our wealth or for me more accurately, our attachments, keep us from following.

Another danger comes after having heard the call, seen the light as it were, accepted the invitation, we are baptized and start off. The danger, as Helen M. Luke ( 1986) has so elegantly stated, is that after we start off, we can become identified and associated with this call as though we were the only one called. Very easily at this point the journey or the dance can be subsumed or subverted by a power drive from the ego. Our noble aspirations may unknowingly be subsumed or subverted by this power drive from the ego.

Direct physical harm alone would be a concern. Deeper harm may occur at the emotional, psychological and/or spiritual levels. As has been said about starting out on the spiritual path in Buddhist teachings: "Better not to begin ... unless you must." But then, once begun, "Better to finish it.” (Schoen 1996) This has been rephrased a slightly different way, but the same intent is there, "It's not whether you win or loose, but how you play the game. However, if you decide to play the game, play to win.”

Here again there is another rejoinder, a warning. It is found for me in Luke 6, v.41-42. To emphasize its importance, the connection of our observing the speck in another's eye as something we have to me mindful of is mentioned twice; in verse 41 "Why do you see the speck ..." and in verse 42 "Brother let me take the speck ...”. In the second half of verse 42, Christ adds the follow up to this warning of seeing the speck in another's eye "when you yourself fail to see the board in your own eye? You hypocrite, first take the board out of your eye, and then you will see clearly to remove the speck from your brother's eye."

The board in our eye is sharply contrasted with the speck in another's eye for good reason. Acknowledging the board(s) in our eyes is about connecting with compassion, humility and empathy, more about relating "with" than "over" or "under" another in terms of the power dynamics. Acknowledging the boards in our own eyes first, in compassion and humility, we are better able to heed the call to take up our crosses to follow Christ for Christ's sake and not for our own sake. This is each and every day of our lives; not just the once. It is reflective of choice, the only freedom. (I mention Christ because of the tradition within which I find myself, but acknowledge the courage and value of paths taken in the name of other great Spiritual figures from other Wisdom traditions.) Admittedly we have to start; "the journey of a thousand miles begins with the first step”. But starting the journey certainly does not finish it. God knows the frustration here. However, acknowledging God's grace, love, and compassion daily is also a requisite for the journey. So, the two admonishments about noticing a speck in someone else's eye, before or without, acknowledging the board(s) in our own eyes reflects the importance of acknowledging the lenses through which we see the world. It is about acknowledging and practicing the importance of including compassion, humility and self-awareness in how we see the world and ourselves. This is the practice of exercising "power with”.

Helen M. Luke addresses this point about the board(s) in our eye very nicely as it relates to projection. "Projection is the way that you see everything that is unconscious in yourself. If you didn't have that projection, you'd never see it. You wouldn't even know you had it.” (1986). If our emotional response toward someone else's actions is way out of proportion with the action (road rage might be a good example of this exacerbation of a perceived wrong or injustice), we are projecting our unconscious foibles onto that other person. Luke continues, "If you find that you hate a person or that there is something that makes you absolutely furious, you may be perfectly sure that it is a part of yourself that is projected there - no matter how true it may be that the other person is behaving badly.” ( 1986). God must see a lot of this projection directed towards heaven as we see it toward others and towards ourselves. 
When this connection between ourselves and someone else is so deep we don't see it consciously, or it appears that our connection with another has been lost, most often our unconscious has been tapped. Luke makes the comment about the consequences of projection. "If you are projecting you are incapable of compassion, you are incapable of understanding that this person is behaving in this way for reasons that you cannot see, from problems that you know nothing about, but that we all share.” ( 1986) This comment is an inspiration for me to bring projection back into my sphere of influence. When I bring projection back into relationship and dialogue with myself, in love and compassion, something holy, integrating and unitive begins to take place. Brokenness in my life becomes visible at the conscious level. Acceptance, healing, and transformation begin to take place in me, in my heart, and hopefully this percolates up to my mind; two among the other "parts" of our constitution which do have to be integrated as they relate with and through Body, Mind, Heart, and Spirit. Helen M. Luke humorously observes, when we take projection back into relationship be begin "to see without getting all het up about it" ( 1986).

I find it humorous and significant that the next passage after that dealing with the board in my eye is about each tree being known by its fruits, in Luke 6:44. "Each tree is recognized by its own fruit.” To the degree that we are able to engage our projections from the unconscious in dialogue, compassion, and love, is the degree that we will be known by our fruits, and to the degree that we will find our true foundation, our true motivation in this life. As T. S. Eliot ( 1944) stated in his poem from the Four Quartets, it is by "the purification of the motive, in the ground of our beseeching" that our true foundation, our true motivation in this life emerges through that which we are being called toward. In reconciling our projections in compassion, and in "purifying our motive in the ground of our beseeching" we may find ourselves in relationship "with" others and indeed with ourselves. This is the shift from "power to" in relationships toward "power with". And we will be known by the fruits of our practice, the fruits of our exercising power in relationships with ourselves and with others. 


\section{References}

Eliot, T. S. 1944, Four Quartets Faber and Faber, Boston, MA.

Glaser, B. G. 2002, "Conceptualization: On theory and theorizing using grounded theory.", International Journal of Qualitative Methods, vol. 1, no. 2, p. Article 3.

James, W. 1958, The Varieties of Religious Experience A Mentor Book, New American Library, New York, NY.

Kisly, L. \& Luke, H. M. 1986, "Letting Go: An Interview With Helen M. Luke," in Leaning on the Moment: Interviews from Parabola, Parabola Books, New York, NY, pp. 251-263.

Schoen, S. 1996, "Gestalt Therapy and Buddhist Teachings," in Transpersonal Psychotherapy, S. Boorstein, ed., State University of New York Press, Albany, NY, pp. 197-207.

Wishart, P. M. 2005, "Conceptualizing Compassionate Power", Spirituality and Health International, vol. 6, no. 1, pp. 33-38.

Paul M. Wishart, BSc, PhD, MA.

President, Spirituality Research Institute (Sri) Inc.

Calgary, AB

Canada $\quad$ T3A 4M1

Phone: $\quad$ (403) 208-3431

E-mail: $\quad$ pmwishart@shaw.ca

Adjunct Assistant Professor, Department of Surgery,

Faculty of Medicine, University of Calgary,

Calgary, AB

Canada $\quad$ T2N 2T9

Phone: $\quad$ (403) $944-1697$

Fax: $\quad$ (403) 270-8409

E-mail: $\quad$ pwishart@ucalgary.ca 